\title{
Effect of Wind Induced Flow in a Closed Density Stratified Water Area Partially Covered with Floating Water Plants
}

\section{Ozaki, Akinori}

Laboratory of Bioproduction and Environment Information Sciences, Division of Bioproduction and Environment Information Sciences, Department of Bioproduction and Bioenvironmental

Sciences, Graduate School of Bioresource and Bioenvironmental Sciences, Kyushu University

\section{Muramatsu, Ryosuke}

Laboratory of Bioproduction and Environment Information Sciences, Division of Bioproduction and Environment Information Sciences, Department of Bioproduction and Bioenvironmental

Sciences, Graduate School of Bioresource and Bioenvironmental Sciences, Kyushu University

Mori, Ken

Laboratory of Bioproduction and Environment Information Sciences, Division of Bioproduction and Environment Information Sciences, Department of Bioproduction and Environmental Science, Faculty of Agriculture, Kyushu University

\section{Inoue, $\mathrm{Eiji}$}

Laboratory of Bioproduction and Environment Information Sciences, Division of Bioproduction and Environment Information Sciences, Department of Bioproduction and Environmental Science, Faculty of Agriculture, Kyushu University

他

https://doi.org/10.5109/24467

出版情報: 九州大学大学院農学研究院紀要. 47 (1)，pp.139-147，2002-10-30. Kyushu University バージョン：

権利関係 : 


\title{
Effect of Wind Induced Flow in a Closed Density Stratified Water Area Partially Covered with Floating Water Plants
}

\author{
Akinori OZAKI*, Ryosuke MURAMATSU*, Ken MORI**, \\ Eiji INOUE and Tomokazu HARAGUCHI
}

\author{
Laboratory of Bioproduction and Environment Information Sciences, Division of Bioproduction and \\ Environment Information Sciences, Department of Bioproduction and Environmental Science, \\ Faculty of Agriculture, Kyushu University, Fukuoka 812-8581, Japan \\ (Received June 28, 2002 and accepted July 12, 2002)
}

\begin{abstract}
Water environmental dynamics in closed water areas with density stratify such as ponds, reservoirs, lakes and estuaries are effected by turbulent flows based on mechanical and thermal disturbances. The thermal disturbance consists of lighting and heating based on solar radiation in the daytime and cooling based on emission at the night. The mechanical disturbance of wind induced flow and wind wave generated by wind action on the surface. We considered the mechanical disturbance of wind induced flow was generated by wind action on the surface in the closed water areas. An experimental investigation of turbulent entrainment induced by the mechanical disturbance was carried out in a laboratory wind -wave tank. We considered that the occupying rate of the floating water plants to the water surface affected on the turbulent entrainment in the closed water area. The results indicated that the existence the floating water plants contributed to make a significant effect on the scale of the turbulent entrainment. It was also found that the entrainment velocity depended on the Richardson number to the power of $-3 / 2$, the stability parameter of density stratified fluid flow.
\end{abstract}

\section{INTRODUCTION}

Water environmental dynamics in closed water areas with density stratification, such as ponds, reservoirs, lakes and estuaries, are affected by turbulent flows that are caused by mechanical and thermal disturbances. The thermal disturbances are due to solar-radiated light and heat in the daytime and cooling from heat and light emissions at night. The mechanical disturbances consist of wind-induced flow and waves. Wind blowing within closed water areas with density stratification gives rise to the entrainment phenomenon at the density interface.

This phenomenon, which is based on the intermixing of the upper and lower water layers, lowers the density interface and affects the water quality. In closed water areas, large numbers of floating water plants grow in summer. These floating water plants can absorb nutrient salts. But these floating water plants block up mechanical disturbance and thermal disturbance in the closed water area. If the surface of closed water areas is partially covered with floating water plants, then the entrainment velocity of the density interface, which is based on the wind-induced flow, is thought to be different from that of

\footnotetext{
* Laboratory of Bioproduction and Environment Information Sciences, Division of Bioproduction and Environment Information Sciences, Department of Bioproduction and Bioenvironmental Sciences, Graduate School of Bioresource and Bioenvironmental Sciences, Kyushu University

** Corresponding author (E-mail: moriken@brs.Kyushu-u.ac.jp)
} 
closed water areas not covered by floating water plants. For the investigation into the these phenomenon, we experimented on wind-wave tank in our laboratory.

In the present investigation, we examined the turbulent structure of wind-induced, density-stratified flow of closed water areas covered with floating water plants.

\section{METHODS AND DATA}

\section{Coefficient of entrainment and overall Richardson number}

Entrainment velocity is generally given by the coefficient of entrainment $E$ and overall Richardson number $R_{u s}$, which are defined as

$$
\left.\begin{array}{l}
E=\frac{u_{e}}{V} \\
R_{i o}=\frac{\Delta \rho g H}{\rho V^{2}}
\end{array}\right\}
$$

where $u_{e}$ is the Entrainment velocity, $V$ is the overall velocity of flow; $H$ is the water depth of the upper layer; $\rho$ is the reference density; $\Delta \rho$ is the difference of density between the upper and lower layer; $g$ and is the gravitational acceleration. On the condition that the water flow is two-dimensional and the section of flowing water under consideration is rectangular, the continuity equation of the flow rate and the density conservation law for the upper layer are respectively given as

$$
\begin{aligned}
& \frac{\partial h_{1}}{\partial t}+\frac{\partial\left(u_{1} h_{1}\right)}{\partial x}=u_{e} \\
& \frac{\partial\left(\rho_{1} h_{1}\right)}{\partial t}+\frac{\partial\left(\rho_{1} u_{1} h_{1}\right)}{\partial x}=\rho_{2} u_{e}
\end{aligned}
$$

where $u_{1}$ is the cross-average velocity of the upper layer; $h_{1}$ is the upper water depth; $\rho_{1}$ is the density of the upper layer; $\rho_{2}$ is the density of the lower layer; $x$ is the mainstream direction; and $t$ is time. In wind-induced flow the second term of the left hand side member of Eq. (2) is small. Hence the entrainment velocity is found to be the rate of variation of the upper water depth with time, i.e., the descending velocity of the density interface, as shown below.

$$
\frac{d h_{1}}{d t}=u_{e}
$$

Eq. (3), by Eq (2) and

$$
\Delta \rho=\rho_{2}-\rho_{1},
$$

yields

$$
\frac{\partial \rho_{1}}{\partial t}+u_{1} \frac{\partial \rho_{1}}{\partial x}=\frac{\Delta \rho}{h_{1}} u_{e}
$$

On the condition that lower water that is entrained to the upper layer is rapidly and uniformly mixed and diffused in the vertical and horizontal direction, Eq. (5) yields 


$$
\frac{d \rho_{1}}{d l}=u_{e} \frac{\Delta \rho}{h_{1}}
$$

From Eq. (4) and Eq. (6), by performing integration under the condition that $\rho_{2}$ is constant, we obtain

$$
h_{1} \Delta \rho=h_{10} \Delta \rho_{0}=\text { const. }
$$

where $h_{10}$ is the initial upper water depth; and is $\Delta \rho_{0}$ the initial difference of density between the upper and lower layer. Hence we can substitute as follows:

$$
H \rightarrow h_{10}, \Delta \rho \rightarrow \Delta \rho_{0}, \rho \rightarrow \rho_{a}, V \rightarrow u_{* a},
$$

where $u_{*_{a}}$ is the air share velocity; and $\rho_{a}$ is the air density.

Thus Eq. (1) can be described below as a time-invariant equation

$$
R_{i u}=\frac{\Delta \rho_{0} g h_{10}}{\rho_{a} u *_{n}^{2}}
$$

and, by Eq. (4), the coefficient of entrainment $E$ can be described as

$$
E=\frac{d h_{1} / d t}{u_{*_{a}}}=\frac{u_{e}}{u_{*_{a}}}
$$

\section{Hydraulic experiments on the entrainment phenomenon}

The wind wave-tank used in the present study consisted of a test tank and wind tunnel. The test tank is composed of an acrylic plate (length $6 \mathrm{~m} \times$ width $0.3 \mathrm{~m} \times$ depth $0.4 \mathrm{~m}$ ). The wind tunnel is composed of a piece of blockboard on the test tank (length $6 \mathrm{~m} \times$ width $0.3 \mathrm{~m} \times$ depth $0.4 \mathrm{~m}$ ) (cf. Fig. 1). A two-layered, stratified density flow is

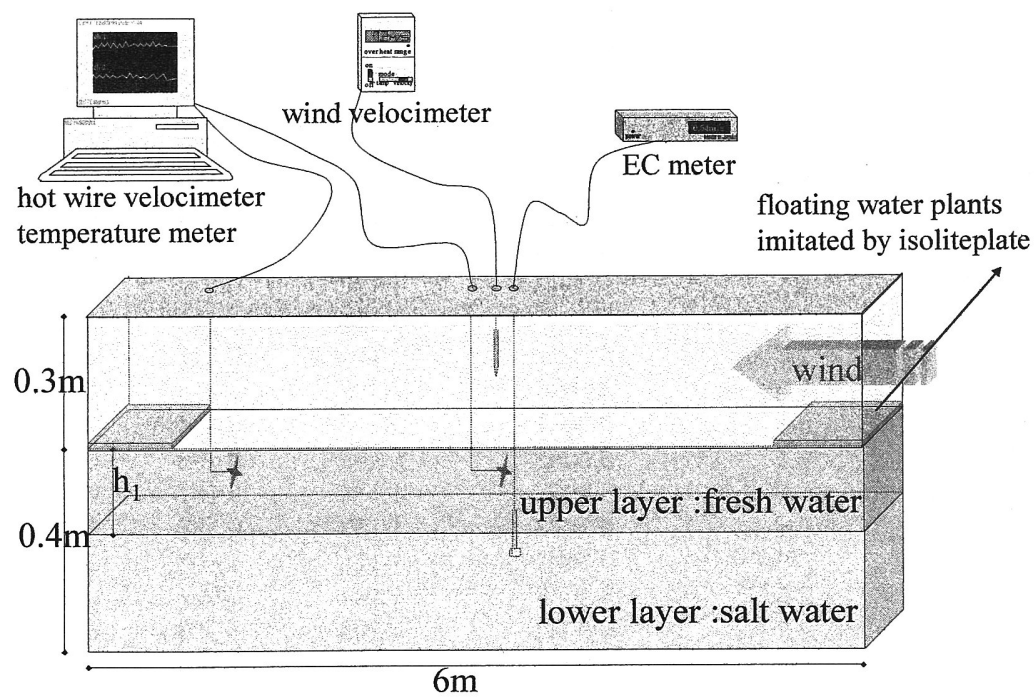

Fig. 1. Experimental equipment 


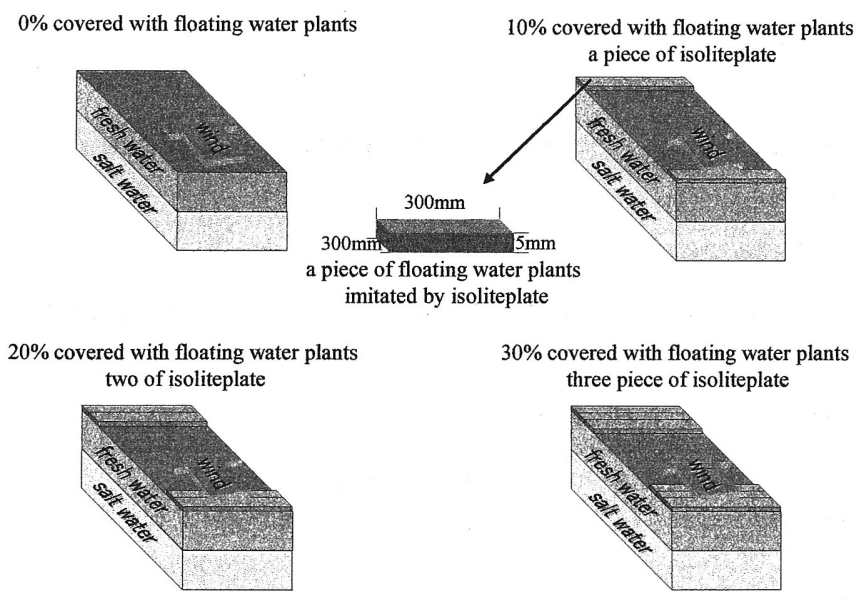

Fig. 2. The way to be covered with floating water plants

Table. 1 Experimental conditions for entrainment phenomenon

\begin{tabular}{|c|c|c|c|c|c|c|c|}
\hline $\begin{array}{l}\text { Run } \\
\text { No. }\end{array}$ & $\begin{array}{l}\text { Covered } \\
\text { Rate }\end{array}$ & $\begin{array}{l}\text { Wind Velocity } \\
\text { Average }(\mathrm{m} / \mathrm{s})\end{array}$ & $\Delta \rho \times 10^{3}\left(\mathrm{~kg} / \mathrm{m}^{3}\right)$ & $\rho_{a}\left(\mathrm{~kg} / \mathrm{m}^{3}\right)$ & $h_{1}(\mathrm{~m})$ & $u \cdot \cdot_{a}(\mathrm{~m} / \mathrm{s})$ & $R_{i a}$ \\
\hline 1 & \multirow[t]{9}{*}{$\beta=10 \%$} & 6.2 & 0.0027 & 1.173 & 0.106 & 0.272 & 31.1 \\
\hline 2 & & 7.2 & 0.0018 & 1.181 & 0.110 & 0.312 & 25.4 \\
\hline 3 & & 6.0 & 0.0013 & 1.168 & 0.100 & 0.261 & 21.1 \\
\hline 4 & & 8.3 & 0.0076 & 1.173 & 0.116 & 0.432 & 39.6 \\
\hline 5 & & 6.8 & 0.0057 & 1.173 & 0.090 & 0.301 & 47.6 \\
\hline 6 & & 7.4 & 0.0049 & 1.175 & 0.110 & 0.376 & 32.3 \\
\hline 7 & & 7.7 & 0.0021 & 1.198 & 0.158 & 0.395 & 17.6 \\
\hline 8 & & 7.9 & 0.0112 & 1.196 & 0.101 & 0.407 & 55.9 \\
\hline 9 & & 7.8 & 0.0107 & 1.195 & 0.084 & 0.401 & 45.8 \\
\hline 10 & \multirow[t]{10}{*}{$\beta=20 \%$} & 6.0 & 0.0076 & 1.190 & 0.100 & 0.261 & 90.1 \\
\hline 11 & & 6.0 & 0.0059 & 1.190 & 0.110 & 0.261 & 80.9 \\
\hline 12 & & 6.0 & 0.0028 & 1.176 & 0.104 & 0.261 & 41.2 \\
\hline 13 & & 7.5 & 0.0080 & 1.183 & 0.107 & 0.488 & 48.8 \\
\hline 14 & & 8.1 & 0.0047 & 1.190 & 0.109 & 0.244 & 24.4 \\
\hline 15 & & 7.9 & 0.0037 & 1.173 & 0.115 & 0.217 & 21.7 \\
\hline 16 & & 7.7 & 0.0027 & 1.194 & 0.141 & 0.201 & 20.1 \\
\hline 17 & & 7.8 & 0.0020 & 1.192 & 0.113 & 0.401 & 12.1 \\
\hline 18 & & 5.2 & 0.0081 & 1.197 & 0.094 & 0.232 & 116.5 \\
\hline 19 & & 5.5 & 0.0058 & 1.203 & 0.108 & 0.257 & 77.4 \\
\hline 20 & \multirow[t]{7}{*}{$\beta=30 \%$} & 5.9 & 0.0058 & 1.188 & 0.101 & 0.258 & 68.4 \\
\hline 21 & & 6.4 & 0.0033 & 1.189 & 0.108 & 0.265 & 35.1 \\
\hline 22 & & 5.9 & 0.0027 & 1.173 & 0.102 & 0.258 & 32.9 \\
\hline 23 & & 7.5 & 0.0059 & 1.194 & 0.094 & 0.382 & 31.4 \\
\hline 24 & & 7.7 & 0.0053 & 1.208 & 0.100 & 0.395 & 27.9 \\
\hline 25 & & 8.1 & 0.0037 & 1.202 & 0.100 & 0.419 & 16.9 \\
\hline 26 & & 7.9 & 0.0028 & 1.197 & 0.110 & 0.408 & 15.3 \\
\hline
\end{tabular}


made in the test tank. The upper layer is fresh water and the lower layer is salt water. To avoid a sudden breaking up of the density interface, a blowing power tank is turned up gradually at the specified wind velocity. The experiment is run on the condition that the over all Richardson number $\left(R_{i a}=\Delta \rho_{0} g h_{10} / \rho_{a} u *_{a}^{2}\right)$ is under 100 for various values of $\beta$. In this equation, $\Delta \rho_{0}$ is the difference of density between the upper and lower layer; $h_{10}$ is the water depth of the upper layer; and $u_{a}$ is the air friction speed. $\beta=100 \times(2 \mathrm{~s} / L)$ is the covered rate of the floating water plants, where $L$ is the length of the test tank; and $s$ is the length of the test tank surface covered with floating water plants. The experimental conditions are shown in Table 1 . The parameters measured are the vertical distribution of wind velocity, the water temperature and the salinity. The wind velocity was measured with a hot-wire velocimeter, the salinity with a conductance meter, and the water temperature with a thermocouple. Fig. 1 shows the profiles of the wind velocity measurements at 3 meters from the windward end of the tank. Salinity and water temperature were measured at 2.75 meters from the windward end. Besides floating water plants are imitated isolite plate. The sections of the plate have thickness of 3 millimeters. In addition, $u_{*_{a}}$ is defined by use of distribution of surface wind complying with logarithmic low. Hence we obtain

$$
U / u_{*_{a}}=(1 / \kappa) \ln \left(z / z_{0}\right)
$$

where $U$ is the wind velocity at height $z ; z$ is the height from the test tank surface; $\kappa$ is the Karman constant; and $z_{0}$ is the roughness constant.

\section{Experimental results}

Fig. 3 shows that the rate of variation of water depth of the upper layer $h_{1}$ with time. The depth $h_{1}$, i.e., the height of the density interface, is shortly after running, severely reduced for a time because of the formation of circulation flow and the development of internal waves, but that this rate is linearly proportion to time. Since a previous experiment without floating water plants (Mori, 1989a) shows the same tendency, we can conclude that lowering velocity of density interface is constant except shortly after running. Hence the entrainment velocity $u_{e}$ in the experiment can also be described as $u_{e}=d h_{1} / d t=$ const.

Fig. 4 shows the relation between the coefficient of entrainment and the overall Richardson number in the present experiment. In Fig. 4 the symbol $\bigcirc$ represents the previously reported experimental results of entrainment velocity in a trial without floating water plants. In the present experiment, the values of $R_{z a}$ ranged from 0 to 100 . In Fig. 4 several interesting phenomena are apparent.

First, the previous result of $E \propto R_{i a}^{-3 R}$ for the trial without floating water plants (Mori, 1989b) are acceptable in this experiment.

Next, the entrainment velocity in the trial with floating water plants is much less than that in the trial without floating water plants under the condition that the overall Richardson number $R_{i a}$ is constant.

Finally, the larger is the covered rate of floating water plants, the lower is the entrainment velocity in the present experiment. Hence, the coefficient of proportioncan $K_{\beta}$ be defined as $E=K_{\beta} R_{r / 2}^{-3 / 2}$.

Fig. 5 shows that the coefficient of proportion $K_{\beta}$ tends to be exponentially lower as 
the covered rate of floating water plants increases. Then, particularly after the circulating flow of the upper layer is established, we conjecture that the entrainment velocity of the two-layered, stratified density interface is bound up with the turbulent structure in the neighborhood of the density interface, i.e., the amount of turbulent flow energy which is produced at the surface of the water and which is transported and diffused into the

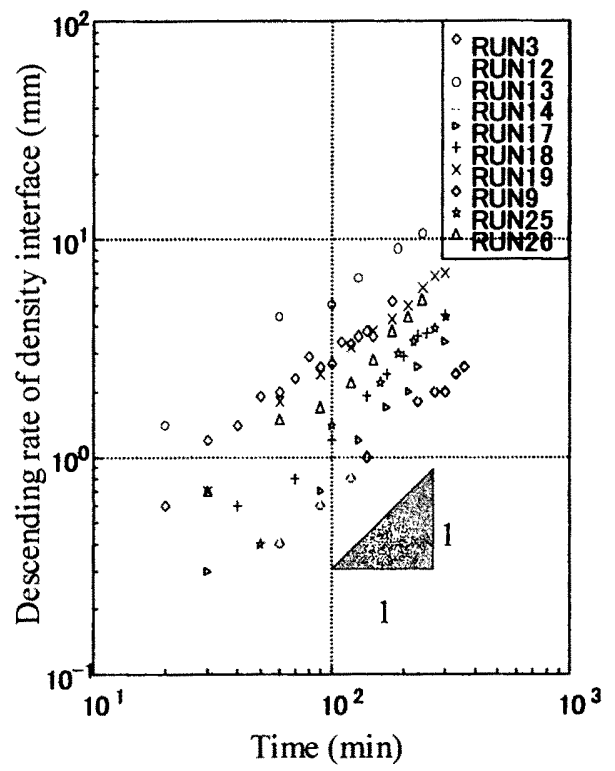

Fig. 3. Variation of interface slope with time for various over all Richardson number

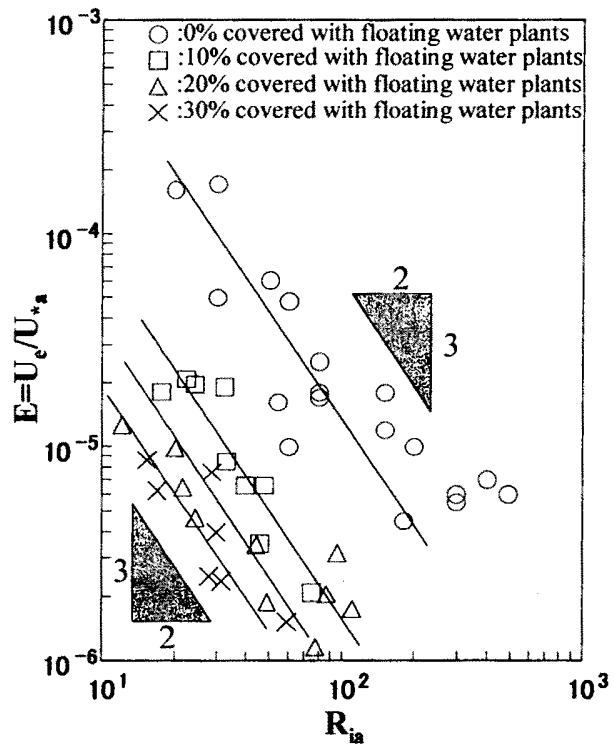

Fig. 4. Entrainment rate $E=u_{\theta} / u_{*_{\alpha}}$ plotted Logarithmically as a function of over all Richardson number $R_{i s}$

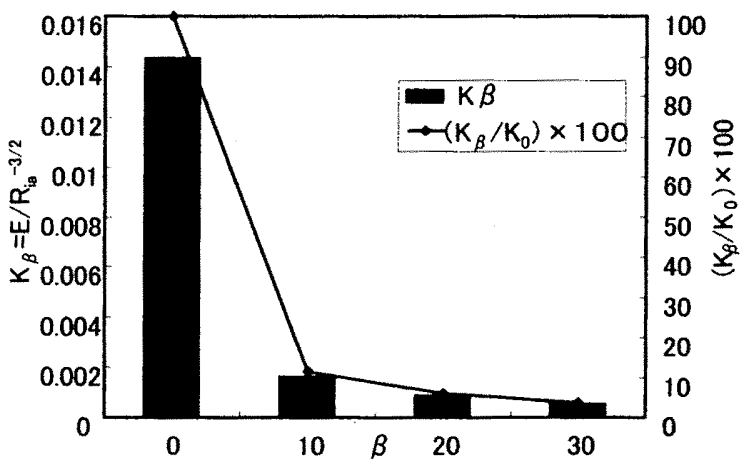

Fig. 5. Experimental data for $K_{\beta}$ as a function of $\beta$ 
neighborhood of the density interface. In addition, the results indicate that the shearing force of wind is lower in the presence of floating water plants than in their absence. This shows that the turbulent energy transported into the neighborhood of the density interface is reduced as the covered rate increases. Now, therefore, in order to clear the variation of the coefficient of proportion stemming from the variation in the covered rate of the floating water plants, we next quantitatively evaluated the turbulent structure of the upper layer for different covered-rate values.

\section{Hydraulics experiment of the turbulent structure in the upper layer}

The equipment and methods for this experiment were the same as for the experiment of the entrainment phenomenon. Vertical and horizontal flow velocity was measured at 5 millimeters intervals from density interface to test tank interface with an X-type hot-wire velocimeter. We set up these equipments at two points, 3 meters from the windward end of the tank (point A) and the edge of the floating water plants (point B). Since entrainment phenomenon has a mutual effect on turbulent structure, we used a sampling time of 30 seconds per measurement. The experimental conditions are shown Table 2. The water share velocity, $u_{*}$, is calculated under a continuous sharing stress at the water surface: $\rho_{a} u_{* a}^{2}=\rho_{1} u_{*}^{2}$

Table. 2 Experimental conditions for turbulent structure

\begin{tabular}{cccccccccc}
\hline $\begin{array}{c}\text { Run } \\
\text { No. }\end{array}$ & $\begin{array}{c}\text { Covered } \\
\text { rate }\end{array}$ & $\begin{array}{c}\text { measurement } \\
\text { point }\end{array}$ & $\begin{array}{c}\text { Wind velocity } \\
\text { average }(\mathrm{m} / \mathrm{s})\end{array}$ & $\Delta \rho\left(\mathrm{kg} / \mathrm{m}^{3}\right) \times 10^{3}$ & $\rho_{a} \times\left(\mathrm{kg} / \mathrm{m}^{3}\right)$ & $h_{10}(\mathrm{~m})$ & $u_{*_{a}}(\mathrm{~m} / \mathrm{s})$ & $u_{*}(\mathrm{~m} / \mathrm{s})$ & $R_{\text {ia }}$ \\
\hline a & $0 \%$ & A & 8.5 & 0.01175 & 1.2365 & 0. & 0. & 0 & 59.3 \\
b & & B & 8.5 & 0.01175 & 1.2365 & 0. & 0. & 0 & 63.6 \\
c & $10 \%$ & A & 8.3 & 0.01154 & 1.2528 & 0. & 0. & 0 & 46.4 \\
d & & B & 8.3 & 0.01154 & 1.2528 & 0. & 0. & 0 & 56.6 \\
e & $20 \%$ & A & 8.3 & 0.01062 & 1.2360 & 0. & 0. & 0 & 45.5 \\
f & & B & 8.3 & 0.01062 & 1.2360 & 0. & 0. & 0 & 51.8 \\
g & $30 \%$ & A & 8.5 & 0.01111 & 1.2365 & 0. & 0. & 0 & 48.1 \\
h & & B & 8.5 & 0.01111 & 1.2365 & 0. & 0. & 0 & 51.2 \\
\hline
\end{tabular}

\section{Experimental Results}

Fig. 6 shows that the increase of the covered rate $\beta$ tends to decrease the value of the two dimensional direction velocity $\sqrt{u^{2}+v^{2}}$ and turbulent intensity at each measure point. And Fig. 6 shows that the changing point from wind-driven current to return current moves upwards to the surface with the increase of value of $\beta$. Fig. 7 shows the profiles of Reynolds stress of the upper layer, where Reynolds stress $\overline{u^{\prime} v^{\prime}}$ is an index of the source of turbulent energy. From Fig. 7, it is observed that there are some outstanding values in the neighborhood of the water surface at A. No other outstanding values are seen, with the exception of those in the neighborhood of the water surface at B. Based on these results, we conclude that the turbulent energy is produced at the water surface and then transported to the lower layer. 
Therefore, from the above-described parameters of turbulent structure, it is confirmed that the increase of the covered rate decreases the turbulent structure at each measured point. These findings suggest that the presence of floating water plants on the surface of the upper layer inhibits the mixing and diffusing of this layer in both the vertical and horizontal directions.
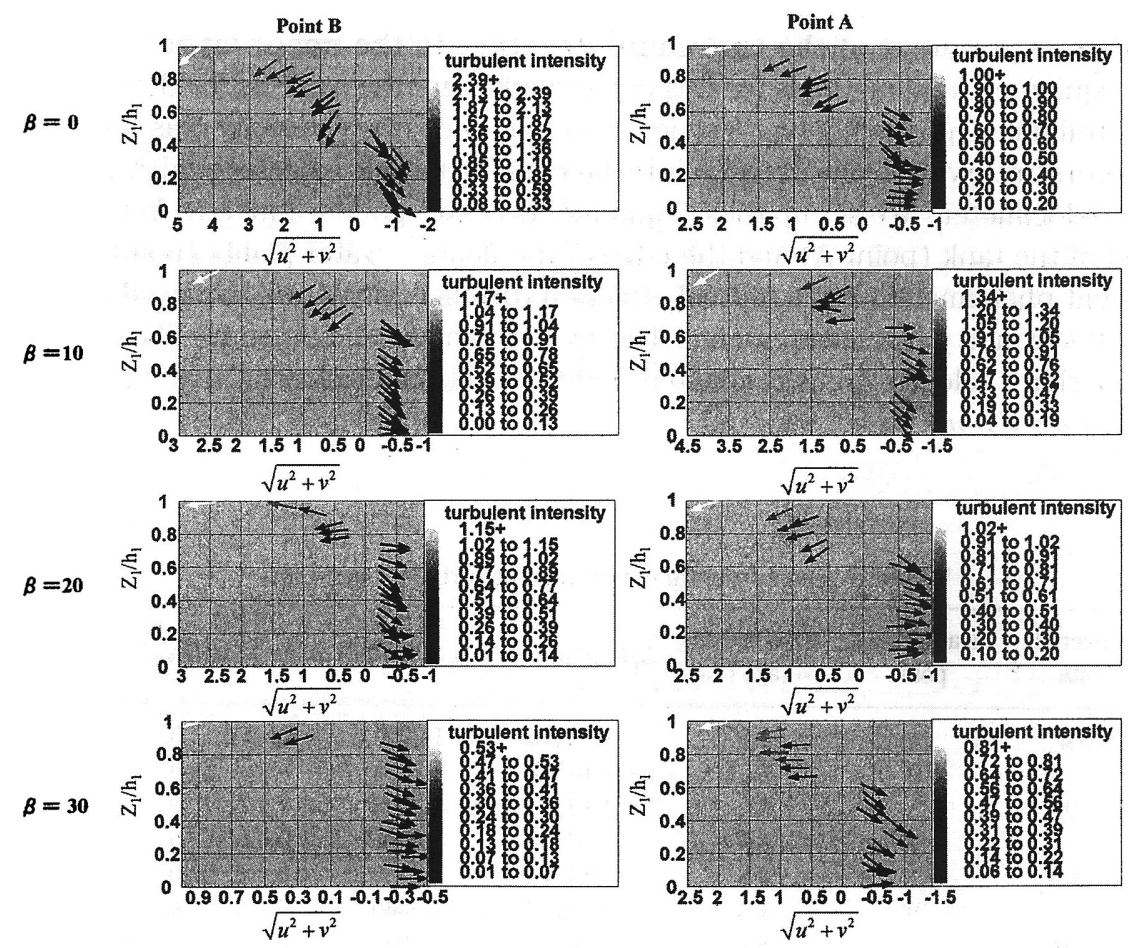

Fig. 6. The profiles of two dimensional direction velocity and turbulent intensity for various values of covered rate

Point B

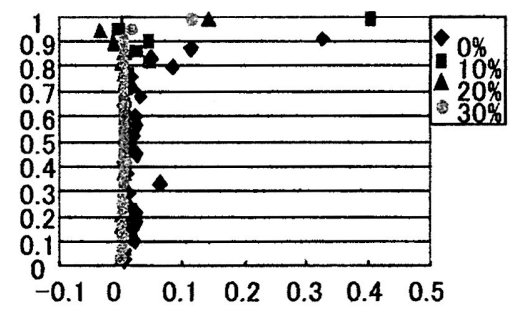

Point A

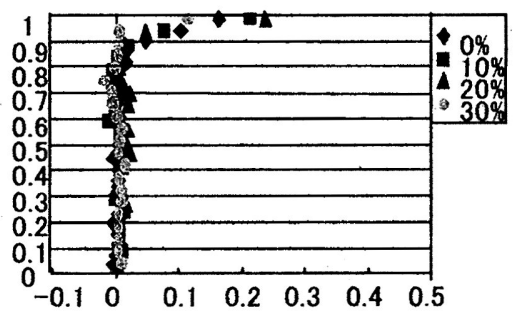

Fig. 7. The profiles of Reynolds stress of the upper layer 


\section{CONCLUSIONS}

Based on the above results, the following conclusions can be drawn:

1. From the experiment of entrainment velocity, the increase of the covered rate $\beta$ of floating water plants decreases the entrainment velocity of the upper layer.

2. From the experiment of turbulent structure, the increase of the covered rate of floating water plants decreases the amount of turbulent energy.

3. The increase of the covered rate $\beta$ of floating water plants decreases the turbulent energy of the upper layer that is produced at the surface. As the turbulent energy is transformed into potential energy, a close relationship between the decrease of entrainment velocity and the turbulent structure is clearly established.

\section{ACKNOWLEDGEMENTS}

The authors wish to thank Laboratory of Drainage and Water Environment, Division of Regional Environmental Science, Department of Bioproducion Environment Science, Faculty of Agriculture, Kyushu University for the convenience in the conducting the experiment.

\section{REFERENCES}

Mori. K Y. Tohara, S. Shikasho, K. Hiramatsu, O. Kato and Y. Cho 1989a Turbulent Structure of Two Layer Stratified Density Flow. Transaction of the Japanese society of irrigation, drainage and reclamation engineering (in Japanese), 144: 75-84.

Mori. K, Y. Tohara and O. Kato 1989b Expcrimental Research of Entrainment Velocity of Density Interface of Wind Current. Transaction of the Japanese society of irrigation, drainage ard reclamation engineering, (in Japanese), 144: 85-93. 